\title{
EFEK PUPUK BOKASHI TERHADAP KETERSEDIAAN UNSUR BASA (K, Na, Ca, dan Mg) PADA INCEPTISOL KARANGPLOSO MALANG
}

\author{
Effects of Bokashi Fertilizer on Availability of Basic Elements \\ $(\mathrm{K}, \mathrm{Na}, \mathrm{Ca}$, and $\mathrm{Mg})$ in an Inceptisol of Karangloso, Malang
}

\author{
Arumita Rohmah, Retno Suntari* \\ ${ }^{1}$ Jurusan Tanah, Fakultas Pertanian, Universitas Brawijaya, Malang 65145 \\ *Penulis Korespondensi: retnosuntari@ub.ac.id
}

\begin{abstract}
The Inceptisol of Karangploso Malang has low pH (5.33) and low C-organic content (1.39\%). Efforts can be made to improve these problems through land management with the use of organic fertilizer. Bokashi is one of the composts produced from fermentation process with EM4 which can improve soil chemical properties, because bokashi has elements of $\mathrm{N}, \mathrm{P}, \mathrm{K}, \mathrm{Na}, \mathrm{Ca}$, and $\mathrm{Mg}$ respectively $1.22 \%, 0.53 \%, 1.71 \%, 5.64 \%, 0.62 \%$ and $2.01 \%$. This study was carried out at the Greenhouse and Chemical Laboratory of Soil Science Department, Agriculture Faculty, Brawijaya University. The design of this research was a completely randomized design with $\mathrm{O} 0$ treatment (control); O1 (Bokashi $5 \mathrm{t} \mathrm{ha}^{-1}$ ); O2 (Bokashi $10 \mathrm{t} \mathrm{ha}^{-1}$ ); O3 (Bokashi $15 \mathrm{t} \mathrm{ha}^{-1}$ ); O4 (Bokashi $20 \mathrm{t} \mathrm{ha}$ 1); O5 (Bokashi $25 \mathrm{t} \mathrm{ha}^{-1}$ ); O6 (Bokashi $30 \mathrm{t} \mathrm{ha}^{-1}$ ) which was repeated 3 times. Parameters measured were $\mathrm{pH}, \mathrm{CEC}, \mathrm{BS}, \mathrm{K}$-exch, Na-exch, $\mathrm{Ca}$-exch, and $\mathrm{Mg}$-exch on $1 \mathrm{MAI}$ (month after incubation), and 2 MAI. The results showed that increasing the dose of bokashi application at 1 MAI significantly increased K-exch and Mg-exch compared to the control treatment, but did not significantly affect $\mathrm{pH}, \mathrm{CEC}, \mathrm{BS}, \mathrm{Na}$-exch, and $\mathrm{Ca}$-exch. Furthermore, increasing the dose of bokashi application on 2 MAI significantly increased $\mathrm{pH}$ and $\mathrm{K}$-exch compared to the control treatment, but did not significantly affect CEC, BS, Na-exch, Ca-exch, and Mg-exch.
\end{abstract}

Keywords : basic nutrients, bokashi, inceptisol

\section{Pendahuluan}

Inceptisol Karangploso Malang mempunyai sifat kimia $\mathrm{pH}$ masam (5,33), C-Organik rendah $(1,39 \%)$, dan bahan organik rendah $(2,41 \%)$. Hal ini sesuai dengan pendapat Dyasmara, Syekhfani dan Nuraini, (2016) bahwa Inceptisol yang terdapat di lahan Dau Malang juga mempunyai sifat kimia $\mathrm{pH}$ masam $(4,75)$ dan C-Organik sangat rendah $(0,57 \%)$. Persebaran Inceptisol di Jawa Timur yang cukup luas dan terdapat permasalahan defisiensi unsur hara, maka upaya yang dapat dilakukan salah satunya melalui pengelolaan lahan dengan penggunaan pupuk organik. Pupuk organik merupakan pupuk yang berasal dari bahan-bahan organik, seperti kotoran ternak maupun limbah hasil panen yang telah dilakukan pengomposan, fermentasi ataupun langsung diaplikasikan pada tanaman. Pupuk organik dapat berupa pupuk hijau, pupuk kandang (pukan), pupuk kompos, maupun pupuk bokashi. Bokashi merupakan salah satu pupuk kompos yang di hasilkan melalui proses fermentasi dengan EM4. Bokashi dapat memperbaiki sifat kimia tanah, sebab bokashi bahan dasar pupuk kandang kotoran kambing, pupuk kandang kotoran sapi dan sekam padi memiliki unsur $\mathrm{N}, \mathrm{P}, \mathrm{K}, \mathrm{Na}, \mathrm{Ca}$, dan $\mathrm{Mg}$ berturut-turut $1,22 \%, 0,53 \%, 1,71 \%, 5,64 \%$, $0,62 \%$ dan $2,01 \%$. Hasil dari beberapa peneliti (Hamied, 2014; Lima et al., 2015) menunjukkan 
bahwa melalui aplikasi bokashi dapat menurunkan unsur $\mathrm{Na}$, berpengaruh nyata terhadap $\mathrm{K}$ dan $\mathrm{Mg}$, dan tidak berpengaruh nyata terhadap $\mathrm{Ca}$.

Menurut Supriyadi (2009) unsur K, Na, $\mathrm{Ca}$ dan $\mathrm{Mg}$ merupakan unsur hara yang ketersediaanya dalam tanah dibutuhkan untuk tanaman. Bokashi merupakan salah satu teknologi pemupukan yang ramah lingkungan untuk mengurangi penggunaan pupuk anorganik dan diharapkan mampu meningkatkan sifat kimia maupun unsur basa dalam tanah.

\section{Bahan dan Metode}

\section{Waktu dan tempat}

Penelitian ini dilakukan di Rumah Kaca dan Laboratorium Kimia Jurusan Tanah Fakultas Pertanian Universitas Brawijaya pada bulan Maret sampai dengan bulan Juli 2018.

\section{Rancangan penelitian}

Rancangan penelitian ini menggunakan Rancangan Acak Lengkap (RAL) dengan 7 perlakuan yang diulang sebanyak 3 kali, sehingga didapatkan 21 perlakuan. Dosis aplikasi bokashi berdasarkan penelitian Amijaya et al. (2015), sedangkan aplikasi pupuk anorganik sesuai rekomendasi BALITSA (2013). Berikut ini merupakan perlakuan dosis aplikasi bokashi: $\mathrm{O} 0=$ Dolomit $2 \mathrm{t} \mathrm{ha}^{-1}+\mathrm{SP} 36$ $100 \mathrm{~kg} \mathrm{ha}^{-1}+$ NPK Mutiara $500 \mathrm{~kg} \mathrm{ha}^{-1}+\mathrm{KCl}$ $60 \mathrm{~kg} \mathrm{ha}{ }^{-1}+$ Urea $180 \mathrm{~kg} \mathrm{ha}{ }^{-1}+$ ZA $400 \mathrm{~kg} \mathrm{ha}^{-1}$, $\mathrm{O} 1=$ Bokashi $5 \mathrm{t} \mathrm{ha}^{-1}+1 / 2$ dosis O0, O2= Bokashi $10 \mathrm{tha}^{-1}+1 / 2$ dosis O0. O3= Bokashi $15 \mathrm{t} \mathrm{ha}^{-1}+1 / 2$ dosis O0, O4= Bokashi $20 \mathrm{t} \mathrm{ha}^{-1}$ $+1 / 2$ dosis O0, O5= Bokashi $25 \mathrm{t} \mathrm{ha}^{-1}+1 / 2$ dosis O0, dan O6= Bokashi $30 \mathrm{t} \mathrm{ha}^{-1}+1 / 2$ dosis $\mathrm{O} 0$

\section{Pengambilan sampel tanah}

Sampel tanah Inceptisols di ambil dari Dusun Leban Desa Tawangargo Kecamatan Karangploso Malang. Sampel tanah diambil pada kedalaman $20 \mathrm{~cm}$ dengan luas lahan 1200 $\mathrm{m}^{2}$ menggunakan metode zig-zag.

\section{Pembuatan pupuk bokashi}

Pembuatan pupuk bokashi dengan menggunakan bahan dasar pukan kotoran sapi, pukan kotoran kambing dan sekam dengan perbandingan (7:7:6). Langkah-langkah pembuatan 1 ton bokashi menurut Irawan (2012) adalah 1) Pukan kotoran sapi sebanyak $350 \mathrm{~kg}$ dan pukan kotoran kambing $350 \mathrm{~kg}$ yang telah disiapkan dihancurkan dengan menggunakan alat penghancur pupuk organik; 2) Ditambahkan sekam sebanyak $300 \mathrm{~kg}$; 3) 1L EM4 dilarutkan kedalam air 300 liter sebagai larutan fermentasi; 4) Semua bahan dihomogenkan dengan larutan fermentasi; 5) Menutup semua bahan yang sudah homogen dengan menggunakan terpal; 6) Melakukan pemeriksaan setiap hari; 7) Melakukan pengadukan apabila suhu dalam pupuk $>50{ }^{\circ} \mathrm{C}$; 8) Diamkan selama 4-7 hari dan Setelah 7 hari bokashi dapat digunakan sebagai pupuk ditandai dengan suhu mencapai $30{ }^{\circ} \mathrm{C}$ dan dapat diaplikasikan ketanah.

\section{Pelaksanaan inkubasi}

Pelaksanaan inkubasi untuk mengetahui ketersediaan unsur basa $(\mathrm{K}, \mathrm{Na} \mathrm{Ca}$ dan $\mathrm{Mg}$ ) dan sifat kimia ( $\mathrm{pH}, \mathrm{KTK}$ dan $\mathrm{KB}$ ) adalah 1)Tanah lolos ayakan $2 \mathrm{~mm}$ sebanyak $0,93 \mathrm{~kg}$ dimasukkan kedalam polybag; 2) Pupuk bokashi ditambahkan sesuai dosis perlakuan; 3) Dihomogenkan dan ditambahkan air bebas ion mencapai kadar air kapasitas lapangan; 4)Setiap minggu dilakukan penimbangan untuk mengetahui kebutuhan air yang akan ditambahkan agar tetap pada kondisi kapasitas lapangan; 5) Sampel tanah diambil dengan cara mengaduk dan mengambil tanah sebanyak $50 \mathrm{~g}$ pada waktu 1 BSI (Bulan Setelah Inkubasi) dan 2BSI.

\section{Analisis laboratorium}

Analisis dasar laboratorium meliputi analisis tanah dan pupuk bokashi. Pengamatan tanah inkubasi dilakukan pada 1 BSI dan 2 BSI. Variabel pengamatan yang diamati antara lain sifat kimia tanah ( $\mathrm{pH}, \mathrm{KTK}$, dan $\mathrm{KB}$ ) dan ketersediaan unsur basa $\left(\mathrm{K}_{\mathrm{dd}}, \mathrm{Nadd}, \mathrm{Ca}_{\mathrm{dd}}\right.$, dan Mgdd).

\section{Analisis data}

Analisis data untuk mengetahui pengaruh perlakuan dengan menggunakan ANOVA (Analysis of variance) dan uji F 5\%. Apabila berpengaruh nyata dilakukan uji lanjut menggunakan DMRT pada taraf 5\%. Analisis 
data tersebut dengan menggunakan softwere Genstat.

\section{Hasil dan Pembahasan}

\section{Analisis dasar tanah}

Hasl analisis dasar tanah disajikan pada Tabel 1. Inceptisol memiliki permasalahan $\mathrm{pH}$ tanah yang masam. Solusi yang dapat dilakukan adalah penambahan pupuk bokashi untuk meningkatkan $\mathrm{pH}$ dan unsur basa dalam tanah.

Tabel 1. Hasil analisis dasar tanah.

\begin{tabular}{|c|c|c|}
\hline Parameter & Satuan & Nilai \\
\hline $\mathrm{pH}\left(\mathrm{H}_{2} \mathrm{O}\right)$ & - & 5,33 \\
\hline C-Organik & $\%$ & 1,39 \\
\hline Bahan Organik & $\%$ & 2,41 \\
\hline $\mathrm{N}$ total & $\%$ & 0,38 \\
\hline $\mathrm{C} / \mathrm{N}$ & $\%$ & 3,66 \\
\hline P-tersedia & $\mathrm{ppm}$ & 91,60 \\
\hline $\mathrm{SO}_{4}^{-}$ & $\mathrm{ppm}$ & 21,57 \\
\hline KTK & me $100 \mathrm{~g}^{-1}$ & 28,98 \\
\hline \multicolumn{3}{|l|}{ Susunan Kation: } \\
\hline $\mathrm{K}_{\mathrm{dd}}$ & me $100 \mathrm{~g}^{-1}$ & 1,05 \\
\hline $\mathrm{Na}_{\mathrm{dd}}$ & me $100 \mathrm{~g}^{-1}$ & 1,23 \\
\hline $\mathrm{Cadd}_{\mathrm{dd}}$ & me $100 \mathrm{~g}^{-1}$ & 12,05 \\
\hline $\mathrm{Mg}_{\mathrm{dd}}$ & me $100 \mathrm{~g}^{-1}$ & 1,94 \\
\hline Kejenuhan Basa & $\%$ & 56,14 \\
\hline \multicolumn{3}{|l|}{ Tekstur: } \\
\hline Pasir & $\%$ & 5 \\
\hline Debu & $\%$ & 85 \\
\hline Liat & $\%$ & 10 \\
\hline
\end{tabular}

\section{Analisis dasar bokashi}

Hasil analisi basar bokashi disajikan pada Tabel 2. Hasil analisis tersebut menunjukkan bahwa pupuk bokashi dengan bahan dasar sekam, pukan kotoran sapi dan pukan kotoran kambing memiliki pH (8,00), C-Organik (16,20\%), N-Total (1,22\%), P-total (0,53\%), dan K-total (1,71\%) yang memenuhi persyaratan teknis minimal pupuk organik (BALITAN, 2009). Hasil analisis bokashi ini mengandung $\mathrm{pH}, \mathrm{C}$-organik, N-total, K-total, Na-total dan Mg-total lebih tinggi dibandingkan bokashi pada penelitian sebelumnya (Solis et al., 2016; Halifah et al., 2014; Simanungkalit et al., 2006).
Tabel 2. Hasil analisis dasar bokashi.

\begin{tabular}{lcr}
\hline Parameter & Satuan & Nilai \\
\hline $\mathrm{pH}\left(\mathrm{H}_{2} \mathrm{O}\right)$ & - & 8,00 \\
$\mathrm{C}$ Organik & $\%$ & 16,20 \\
Bahan Organik & $\%$ & 28,03 \\
N-total & $\%$ & 1,22 \\
$\mathrm{C} / \mathrm{N}$ & $\%$ & 13,27 \\
P-total & $\%$ & 0,53 \\
KTK & $100 \mathrm{~g}^{-1}$ & 38.44 \\
K-total & $\%$ & 1,71 \\
Na-total & $\%$ & 5,64 \\
Ca-total & $\%$ & 0,62 \\
Mg-total & $\%$ & 2,01 \\
S-total & $\%$ & 0,25 \\
\hline
\end{tabular}

Pengaruh bokashi terhadap pH, kapasitas tukas kation (KTK, dan kejenuhan bada (KB) tanah

pH tanah

$\mathrm{pH}$ tanah dapat digunakan sebagai indikator kesuburan kimia tanah. Pengukuran $\mathrm{pH}$ dilakukan untuk mengetahui tingkat kebasaan ataupun kemasaman tanah. Hasil dari analisis ragam menunjukkan bahwa aplikasi bokashi pada pengamatan 1 BSI tidak berpengaruh nyata dan 2 BSI berpengaruh nyata terhadap $\mathrm{pH}$ di Inceptisols. Rerata hasil analisis pengaruh bokashi terhadap $\mathrm{pH}$ tanah (Tabel 3). Hasil uji DMRT 5\% pada 2 BSI perlakuan O0 (kontrol) tidak berbeda nyata dengan O1, O2, O3 dan O4, akan tetapi perlakuan O5 (25 t $\mathrm{ha}^{-1}$ ) dan O6 (30 $\mathrm{t} \mathrm{ha}^{-1}$ ) berbeda nyata dengan perlakuan $\mathrm{O} 0$ (kontrol).

Kondisi awal tanah memiliki nilai $\mathrm{pH}$ dalam kriteria masam (5,33), setelah diaplikasikan bokashi tetap sama dengan analisis dasar dalam kriteria masam. Hal ini disebabkan oleh bokashi yang diaplikasikan mengalami dekomposisi yang menghasilkan $\mathrm{CO}_{2}$, apabila $\mathrm{CO}_{2}$ bereaksi dengan air yang membentuk $\mathrm{H}_{2} \mathrm{CO}_{3}$ dan akan terurai menjadi $\mathrm{HCO}_{3}+\mathrm{H}^{+}$yang menyebabkan tanah menjadi masam. Selain itu, Penyangga bahan organik berasal dari gugus fungsi asam lemah (gugus karboksilat dan gugus fenolik) ketika ditambahkan proton dan menerima proton dari penambahan asam organik maka dihasilkan kondisi tanah masam seperti proses mineralisasi N (Curtin dan Trolove, 2013). 
Tabel 3. Rerata hasil analisis pengaruh bokashi terhadap $\mathrm{pH}$ kapasitas tukas kation (KTK, dan kejenuhan bada (KB) tanah.

\begin{tabular}{ccccccc}
\hline \multirow{2}{*}{ Perlakuan } & \multicolumn{2}{c}{$\mathbf{p H}$ Tanah } & \multicolumn{2}{c}{ KTK (me 100 $\mathbf{g}^{-\mathbf{1}} \mathbf{c}$} & \multicolumn{2}{c}{ KB (\%) } \\
\cline { 2 - 7 } & 1 BSI & 2 BSI & 1 BSI & 2 BSI & 1 BSI & 2 BSI \\
\hline O0 & 5,14 & $5,11 \mathrm{a}$ & 37,34 & 41,36 & 41,75 & 40,62 \\
O1 & 5,31 & $5,25 \mathrm{ab}$ & 37,35 & 43,96 & 38,38 & 35,68 \\
O2 & 5,19 & $5,13 \mathrm{a}$ & 39,22 & 44,63 & 39,59 & 39,06 \\
O3 & 5,20 & $5,19 \mathrm{a}$ & 40,27 & 44,77 & 43,06 & 38,48 \\
O4 & 5,35 & $5,19 \mathrm{a}$ & 43,29 & 45,21 & 42,35 & 42,92 \\
O5 & 5,33 & $5,36 \mathrm{~b}$ & 42,68 & 43,32 & 43,62 & 46,06 \\
O6 & 5,36 & $5,35 \mathrm{~b}$ & 39,79 & 41,56 & 45,60 & 45,06 \\
\hline
\end{tabular}

Keterangan: Angka yang didampingi huruf yang sama pada kolom yang sama, tidak berbeda nyata (DMRT $5 \%)$.

\section{KTK tanah}

KTK merupakan kemampuan tanah dalam menjerap dan mempertukarkan kation dalam tanah. Hasil analisis ragam menunjukkan bahwa aplikasi bokashi tidak berpengaruh nyata pada 1 BSI maupun 2 BSI terhadap nilai KTK tanah. Rerata hasil analisis pengaruh bokashi terhadap KTK (Tabel 3). Nilai KTK hasil analisis awal (Tabel 1) menunjukkan kriteria nilai KTK tinggi $\left(29,98 \mathrm{me} 100 \mathrm{~g}^{-1}\right)$. Setelah diaplikasikan bokashi pada 1 BSI dan 2 BSI mengalami peningkatan nilai KTK tanah dari kriteria tinggi hingga sangat tinggi. Hal ini disebabkan oleh aplikasi bokashi dengan berbagai dosis dapat menjerap dan melepaskan kation-kation dalam tanah. Anwar dan Sudadi (2013) menyatakan bahwa KTK tanah secara umum dapat bersumber dari koloid bahan organik tanah. KTK yang meningkat dipengaruhi oleh dekomposisi bahan organik yang menghasilkan senyawa humik. Senyawa ini dapat menyumbangkan koloid tanah yang mampu meningkatkan KTK dengan bertambahnya muatan negatif dari gugus karboksil $(\mathrm{COOH})$ dan hidroksil $(\mathrm{OH})$ (Siregar et al., 2017). Peningkatan KTK dapat menyebabkan tanah menjadi subur. KTK dapat mempertukarkan kation basa seperti $\mathrm{K}, \mathrm{Na}, \mathrm{Ca}$ dan $\mathrm{Mg}$ yang akan meningkatkan kejenuhan basa dan meningkatkan kesuburan tanah..

Kejenuhan basa (KB) tanah

$\mathrm{KB}$ menunjukkan perbandingan jumlah kation basa dengan jumlah kation yang terikat pada kation tanah yang dihasilkan dalam satuan persen. Hasil analisis ragam menunjukkan bahwa aplikasi bokashi tidak berpengaruh nyata pada 1 BSI dan 2 BSI terhadap nilai KB tanah. Rerata hasil analisis pengaruh bokashi terhadap KB (Tabel 3). Nilai KB hasil analisis dasar tanah (Tabel 1) menunjukkan kriteria sedang $(56,14 \%)$. Setelah aplikasi bokashi pada 2 BSI perlakuan O0, O4, O5 dan O6 tetap menghasilkan kriteria sedang yang sama dengan analisis dasar tanah (Tabel 1), akan tetapi pada perlakuan O1, O2, dan O3 mengalami penurunan kriteria menjadi rendah. Hal ini disebabkan oleh hasil jumlah kation basa lebih rendah dari pada hasil nilai KTK, maka nilai KB menjadi rendah. Nilai KB yang rendah ini disebabkan pertukaran kation didominasi oleh kation asam. Menurut penelitian Sembiring, Wawan dan Khoiri (2015) menyatakan bahwa tanah dengan kejenuhan basa rendah, berarti kompleks jerapan lebih dominan diisi oleh kation asam yaitu $\mathrm{H}^{+}$dan $\mathrm{Al}^{+}$. Selain itu, $\mathrm{KB}$ yang rendah dapat disebabkan tanah yang diaplikasikan bokashi memiliki nilai $\mathrm{pH}$ yang masam, sehingga kation $\mathrm{H}^{+}$lebih dominan dari pada kation basa yang menyebabkan jumlah nilai kation basa rendah.

\section{Pengaruh bokashi terhadap $\mathrm{K}_{d d}, \mathrm{Na}_{d d}, \mathrm{Ca}_{d d}$ dan $M g_{d d}$ tanah}

\section{$K_{d d}$, tanah}

$K_{\text {dd }}$ merupakan salah satu unsur hara makro esensial yang diserap tanaman dalam bentuk $\mathrm{K}^{+}$. Hasil analisis ragam menunjukkan bahwa aplikasi bokashi pengaruh sangat nyata pada 1 BSI dan berpengaruh nyata pada 2 BSI terhadap $K_{d d}$ tanah. Rerata hasil analisis pengaruh bokashi terhadap $K_{d d}$ (Tabel 4). 
Hasil dari uji DMRT 5\% pengaruh bokashi terhadap $K_{\text {dd }}$ pada 1 BSI menunjukkan bahwa perlakuan O1 memiliki nilai yang terendah. Perlakuan O0, O2 dan O3 menujukkan hasil nilai $\mathrm{K}_{\mathrm{dd}}$ tidak berbeda nyata, sedangkan perlakuan O6 dan O5 berbeda nyata dengan perlakuan O0 (kontrol). Selanjutnya pengaruh bokashi terhadap $K_{\text {dd }}$ pada 2 BSI menunjukkan bahwa perlakuan O1 tetap berada pada nilai terendah dan tidak berbeda nyata dengan perlakuan O0 (kontrol), Kemudian O5 dan O6 tetap pada nilai tertinggi dan berbeda nyata dibanding perlakuan O0 (kontrol). Aplikasi bokashi disemua perlakuan menyebabkan nilai $\mathrm{K}_{\text {dd }}$ dalam kriteria sangat tinggi $(>1 \mathrm{me} 100 \mathrm{~g}-$ 1). Hal ini membuktikan bahwa peningkatan dosis aplikasi bokashi sampai 30 ton ha ${ }^{-1}$ pada 1 BSI dan 2 BSI tidak menambahkan kriteria nilai $K_{\mathrm{dd}}$. Pembuatan bokashi dilakukan dengan cara fermentasi menggunakan EM4 yang dapat mempercepat proses dekomposisi, sehingga hasil dekomposis yang berupa humus dapat meningkatkan unsur hara. Bahan organik yang sudah stabil (humus) berfungsi menjerap dan menahan unsur hara dalam bentuk tersedia (Hartatik, Husnain dan Widowati, 2015).

Tabel 4. Rerata hasil analisis pengaruh bokashi terhadap $K_{d d}$ tanah.

\begin{tabular}{|c|c|c|c|c|c|c|c|c|}
\hline \multirow[t]{2}{*}{ Perlakuan } & \multicolumn{2}{|c|}{$\begin{array}{c}K_{\mathrm{dd}} \\
\left(\mathrm{me} 100 \mathrm{~g}^{-1}\right)\end{array}$} & \multicolumn{2}{|c|}{$\begin{array}{c}\mathrm{Na}_{\mathrm{dd}} \\
\left(\mathrm{me} 100 \mathrm{~g}^{-1}\right)\end{array}$} & \multicolumn{2}{|c|}{$\begin{array}{c}\mathrm{Ca}_{\mathrm{dd}} \\
\left(\mathrm{me} 100 \mathrm{~g}^{-1}\right)\end{array}$} & \multicolumn{2}{|c|}{$\begin{array}{c}\mathbf{M g}_{\mathrm{dd}} \\
\left(\mathrm{me} 100 \mathrm{~g}^{-1}\right)\end{array}$} \\
\hline & $1 \mathrm{BSI}$ & $2 \mathrm{BSI}$ & $1 \mathrm{BSI}$ & 2 BSI & $1 \mathrm{BSI}$ & 2 BSI & $1 \mathrm{BSI}$ & 2 BSI \\
\hline O0 & $1,71 \mathrm{~b}$ & $1,47 \mathrm{ab}$ & 1,52 & 0,74 & 10,34 & 12,33 & $2,01 \mathrm{a}$ & 2,27 \\
\hline O1 & $1,27 \mathrm{a}$ & $1,28 \mathrm{a}$ & 1,50 & 0,75 & 9,71 & 11,13 & $1,90 \mathrm{a}$ & 2,41 \\
\hline $\mathrm{O} 2$ & $1,80 \mathrm{~b}$ & $1,91 b c$ & 1,54 & 0,87 & 9,96 & 11,49 & $2,25 a$ & 3,13 \\
\hline O3 & $1,95 b c$ & $1,90 \mathrm{bc}$ & 1,70 & 0,91 & 10,04 & 11,53 & $3,61 \mathrm{~b}$ & 2,79 \\
\hline O4 & $2,23 c$ & $1,96 \mathrm{bc}$ & 1,84 & 0,92 & 10,94 & 12,26 & $3,31 \mathrm{~b}$ & 4,19 \\
\hline O5 & $2,88 \mathrm{~d}$ & $2,07 \mathrm{c}$ & 2,13 & 0,99 & 10,58 & 12,41 & $3,04 \mathrm{~b}$ & 4,39 \\
\hline O6 & $2,63 \mathrm{~d}$ & $2,25 c$ & 1,99 & 1,03 & 9,97 & 12,02 & $3,43 \mathrm{~b}$ & 3,38 \\
\hline
\end{tabular}

Keterangan: Angka yang didampingi huruf yang sama pada kolom yang sama, tidak berbeda nyata (DMRT $5 \%)$.

\section{Nadd tanah}

$\mathrm{Na}$ merupakan unsur hara fungsional yang ketersediaannya dapat membantu unsur $\mathrm{K}$ dalam tanah. Berdasarkan hasil analisis ragam menunjukkan bahwa aplikasi bokashi tidak berpengaruh nyata pada 1 BSI dan 2 BSI terhadap $\mathrm{Na}_{\mathrm{dd}}$ tanah. Rerata hasil analisis pengaruh bokashi terhadap $\mathrm{Na}_{\mathrm{dd}}$ (Tabel 4). Nilai $\mathrm{Na}_{\text {dd }}$ hasil analisis dasar tanah (Tabel 1) dan 1 BSI menunjukkan kriteria sangat tinggi (>1 me $\left.100 \mathrm{~g}^{-1}\right)$. Setelah aplikasi bokashi pada 2 BSI mengalami penurunan nilai $\mathrm{Nadd}$ dari sangat tinggi menjadi tinggi dan sedang. Penurunan nilai $\mathrm{Na}_{\mathrm{dd}}$ tidak akan mempengaruhi kesuburan di tanah tersebut, sebab $\mathrm{Na}$ bukan merupakan unsur hara esensial yang dibutuhkan oleh tanaman. Oleh sebab itu dengan penambahan bahan organik pada lahan masam dapat menambah energi mikroorganisme untuk menghasilkan senyawa organik yang diperlukan tanah (Muzaiyanah dan Subandi, 2016). Penelitian yang dilakukan oleh El-Shafei (2008) menyatakan bahwa aplikasi 4 ton kompos mampu menurunkan $\mathrm{Na}$ dalam tanah sebesar 5,6\%. Hal ini disebabkan EM yang digunakan pada saat pengomposan mengandung bakteri yang menetralkan garamgaram di dalam tanah.

$C a_{d d}$ tanah

Cadd merupakan salah satu unsur hara makro esensial yang dibutuhkan tanaman untuk merangsang pembentukan biji (Supriyadi, 2009). Hasil analisis ragam menunjukkan bahwa aplikasi bokashi tidak berpengaruh nyata pada 1 BSI dan 2 BSI terhadap $\mathrm{Ca}_{\mathrm{dd}}$ tanah. Rerata hasil analisis pengaruh bokashi terhadap $\mathrm{Ca}_{\mathrm{dd}}$ (Tabel 4). Nilai Cadd hasil analisis dasar tanah (Tabel 1) menunjukkan kriteria tinggi (12,05 me $\left.100 \mathrm{~g}^{-1}\right)$. Setelah aplikasi bokashi menunjukan bahwa nilai $\mathrm{Ca}_{\mathrm{dd}}$ pada 1 BSI dalam kriteria sedang dan pada 2 BSI mengalami peningkatan kriteria menjadi tinggi. 


\section{Jurnal Tanah dan Sumberdaya Lahan Vol 6 No 2 : 1273-1279, 2019 e-ISSN:2549-9793, doi: 10.21776/ub.jts1.2019.006.2.8}

Aplikasi bokashi ini merupakan salah satu pupuk organik yang dapat meningkatkan kesuburan pada tanah. Penurunan $\mathrm{Ca}_{\mathrm{dd}}$ pada 1 BSI dan peningkatan $\mathrm{Ca}_{\mathrm{dd}}$ pada 2 BSI disebabkan aplikasi bokashi akan mengalami dekomposisi dan menghasilkan kation yang tersedia. Menurut Rosmarkam dan Yuwono (2002) bahan organik dalam proses mineralisasi akan melepaskan hara tanaman yang lengkap, seperti N, P, K, Ca dan Mg dalam jumlah yang tidak tentu. Kemudian aplikasi bokashi dengan dosis yang meningkat tidak signifikan mempengaruhi peningkatan $\mathrm{Ca}_{\mathrm{dd}}$. Hal ini sesuai dengan pernyataan Lima et al. (2015) bahwa aplikasi bokashi tidak meningkatkan Ca dalam tanah, sehingga perlu ditambahkan pengapuran ataupun pemupukan dari sumber lain.

$M g_{d d}$ tanah

$\mathrm{Mg}$ diambil tanaman dalam bentuk ion $\mathrm{Mg}^{2}$. Hasil analisis ragam menunjukkan bahwa aplikasi bokashi berpengaruh sangat nyata pada 1 BSI dan tidak berpengaruh nyata pada 2 BSI terhadap $\mathrm{Mg}_{\mathrm{dd}}$ tanah Inceptisols. Rerata hasil analisis pengaruh bokashi terhadap $\mathrm{Mg}_{\mathrm{dd}}$ (Tabel 4). Nilai $\mathrm{Mg}_{d d}$ hasil uji DMRT 5\% pada 1 BSI menunjukkan berbeda sangat nyata $(p<0,01)$. Perlakuan O0 (kontrol) tidak berbeda nyata dengan $\mathrm{O} 1$ dan $\mathrm{O} 2$, akan tetapi perlakuan $\mathrm{O} 3$, O4, O5 dan O6 berbeda nyata dengan perlakuan O0 (kontrol). Selanjutnya nilai $\mathrm{Mg}_{\mathrm{dd}}$ pada 2 BSI menunjukkan hasil tidak berbeda nyata, hal ini disebabkan oleh aplikasi bokashi dengan dosis yang semakin tinggi tidak dipengaruhi nilai $\mathrm{Mg}_{\text {dd, }}$ akan tetapi tetap pada kriteria yang sama (tinggi). Nilai $\mathrm{Mg}_{\mathrm{dd}}$ hasil analisis awal sebelum aplikasi bokashi (Tabel 1)

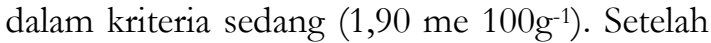
dilakukan aplikasi bokashi menunjukan bahwa nilai $\mathrm{Mg}_{\text {dd }}$ pada 1 BSI dan 2 BSI mengalami peningkatan kriteria dari sedang menjadi tinggi. Bahan organik mengandung unsur $\mathrm{Mg}_{\mathrm{dd}}$, sehingga apabila bahan organik yang diaplikasikan ke dalam tanah yang mengandung $\mathrm{Mg}_{\mathrm{dd}}$ tinggi maka diharapkan kandungan $\mathrm{Mg}$ juga bertambah. Oleh sebab itu, bokashi yang diaplikasikan ke dalam tanah akan menyebabkan bertambahnya kandungan $\mathrm{Mg}_{\mathrm{dd}}$ pada tanah, sehingga nilai $\mathrm{Mg}_{\mathrm{dd}}$ mengalami peningkatan kriteria.

\section{Kesimpulan}

Aplikasi bokashi dengan dosis yang meningkat berpengaruh nyata meningkatkan $\mathrm{pH}$ (dari 5,11 menjadi 5,36) pada 2 BSI dibanding kontrol, akan tetapi tidak berpengaruh nyata terhadap KTK maupun KB pada 1 BSI dan 2 BSI. Aplikasi bokashi dengan dosis yang meningkat pada 1 BSI berpengaruh nyata meningkatkan $K_{\text {dd }}$ (dari 1,71 me $100 \mathrm{~g}^{-1}$ menjadi 2,88 me 100 $\mathrm{g}^{-1}$ ) dan $\mathrm{Mg}_{\text {dd }}$ (dari 2,01 me $100 \mathrm{~g}^{-1}$ menjadi 3,43 me $100 \mathrm{~g}^{-1}$ ) dibanding perlakuan kontrol, akan tetapi tidak berpengaruh nyata terhadap $\mathrm{Na}_{\mathrm{dd}}$ dan Cadd. Selanjutnya aplikasi bokashi dengan dosis yang meningkat pada 2 BSI berpengaruh nyata meningkatkan $K_{\text {dd }}$ (dari 1,47 me $100 \mathrm{~g}^{-1}$ menjadi 2,25 me $100 \mathrm{~g}^{-1}$ ) dibanding perlakuan kontrol, akan tetapi tidak berpengaruh nyata terhadap $\mathrm{Na}_{\mathrm{dd}}$, Cadd, dan $\mathrm{Mg}_{\mathrm{dd}}$.

\section{Daftar Pustaka}

Amijaya, M., Dunga, Y.P. dan Thaha, A.R. 2015. Pengaruh pupuk kandang sapi terhadap serapan posfor dan hasil tanaman bawang merah (Allium ascalonicum L.) varietas Lembah Palu di Entisols Sidera. e-Jurnal Agrotekbis 3 (2): 187-197.

Anwar, S., dan Sudadi, U. 2013. Kimia Tanah. Departemen Ilmu Tanah dan Sumberdaya Lahan IPB. Bogor. p 75.

Balai Penelitian Tanah (BALITAN). 2009. Analisis Kimia Tanah, Tanaman, Air, dan Pupuk. Balai Penelitian Sumber Daya Lahan Pertanian. Bogor. $\mathrm{p}$ 211

Curtin, D. and Trolove., S. 2013. Predicting pH buffering capacity of new zealand soils from organic matter content and mineral characteristics. Journal Compilation 51: 494-502.

Dyasmara, S.P., Syekhfani dan Nuraini, Y. 2016. Efektivitas kompos campuran ampas teh, kotoran sapi dan kotoran kambing terhadap serapan $\mathrm{n}$ pada tanaman bawang daun pada inceptisols. Jurnal Tanah dan Sumberdaya Lahan 3 (1): 285-292.

El-Shafei, A., Yehia, M. and El-Naqib, F. 2008. Impact of effective microorganisms compost on soil fertility and rice productivity and quality. Misr Journal of Agricultural Engineering, 25(3): 1067- 1093.

Halifah, U.N., Soelistyono. R. dan Santoso, M. 2014. Pengaruh pemberian pupuk organik (blotong) dan pupuk anorganik (ZA) terhadap tanaman bawang merah. Jurnal Produksi Tanaman 2 (8): 665-672. 
Hamied, S.A.A.E. 2014. Effect of multi-ingredient of bokashi on productivity of mandarin trees and soil properties under saline water irrigation. Journal of Agriculture and Veterinary Science 7 (11): 79-87.

Hartatik, W., Husnain. dan Widowati, L.R. 2015. Peranan pupuk organik dalam peningkatan produktivitas tanah dan tanaman. Jurnal Sumberdaya Lahan 2 (9): 107-120.

Irawan, U.S. 2012. Teknik Pembuatan Pupuk Bokashi. Embassy of Denmark DANIDA. Jakarta. p 3-7.

Lima, C.E.P., Fontenelle, M.R., Silva, L.R.B., Soares, D.C., Moita., A.W., Zandonadi, D.B., Sauza, R.B. and Lopes, C.A. 2015. Short-term changes in fertility attributs and soil organic matter caused by the addition of EM bokashi in two tropical soils. International Journal of Agronomy 10: 1-9.

Muzaiyanah, S. dan Subandi. 2016. Peranan bahan organik dalam peningkatan produksi kedelai dan ubi kayu pada lahan kering masam. Jurnal Iptek Tanaman Pangan 11 (2): 149-157.

Rosmarkam, A. dan Yuwono, N.W. 2002. Ilmu Kesuburan Tanah. Kanisius. Yogyakarta. p 104109.
Sembiring, I.S., Wawan, dan Khoiri, M.A. 2015. Sifat kimia tanah Dystrudepts dan pertumbuhan akar tanaman kelapa sawit (Elasis guineensis Jacq.) yang diaplikasikan mulsa organik. JOM FAPERTA. 2 (2): 1-11.

Simanungkalit, R.D.M., Suriadikarta, D.A., Saraswati, R., Setyorini, dan Hartatik, W. 2006. Pupuk Organik dan Pupuk Hayati. Balitbang Sumberdaya Lahan Pertanian. Bogor. p 335-342.

Siregar, P., Fauzi. dan Supriadi. 2017. Pengaruh pemberian beberapa sumber bahan organik dan masa inkubasi terhadap beberapa aspek kimia kesuburan tanah ultisol. Jurnal Agroekoteknologi FP USU. 5 (2): 256-264.

Solis, J.D.A., Nunez, J.A.M., Martinez, N.S.L., Albores, J.C. and Miceli, F.A.G. 2016. Effect of bokashi and vermicompost leachate on yield and quality of pepper (Capsicum annuum) and onion (allium cepa) under monoculture and intercropping cultures. Ciencia e Investigacion Agraria. 43 (2): 243- 252.

Supriyadi, S. 2009. Status unsur-unsur basa $\left(\mathrm{Ca}^{2+}\right.$, $\mathrm{Mg}^{2+}, \mathrm{K}^{+}$, dan $\mathrm{Na}^{+}$) di lahan kering Madura. Jurnal Agrovigor 2 (1): 35-41. 